\title{
VERGÍLIO FERREIRA: DO PENSAMENTO À ESCRITA
}

\author{
Rosa Maria Goulart*
}

\begin{abstract}
Resumo: Depois de ter escrito os nove volumes de Conta-Corrente, Vergílio Ferreira continua, com Pensar (1992) e Escrever (2001), a dar forma literária à sua apetência pela escrita diarística. Em fragmentos numerados, mas não datados, estes diários «do acaso de ir pensando» dizem não o vivido no quotidiano, como é próprio do diário mais ortodoxo, mas um pensamento em acção e uma escrita em acto. Aí prossegue Vergílio uma reflexão que se exerce num discurso oscilante entre o diário, propriamente dito, e o ensaio, de que não está ausente uma notória dimensão estética.
\end{abstract}

PALAVRAS-CHAVE: Vergílio Ferreira, diário, ensaio, fragmento, pensar e escrever.

RÉSUMÉ: Après avoir écrit les neuf volumes de Conta-Corrente, Vergílio Ferreira continue avec Penser (1992) et Écrire (2001) - à donner une forme littéraire à son gô̂t de l'écriture du journal intime. À travers des fragments numérotés, mais non pas datés, ces journaux nés " de ce que traverse l'esprit par hasard» parlent non pas de ce qui est vécu au jour le jour, tel que l'on trouverait dans un journal intime orthodoxe, mais d'une pensée en action et d'une écriture en acte. Vergílio Ferreira y poursuit une réflexion qui se bâtit sur un discours qui oscille entre le journal tout court et l'essai, d'où l'on ne saurait exclure une dimension esthétique réelle.

Mотs-CLÉs: Vergílio Ferreira, journal intime, essai, fragment, penser et écrire.

Secundando, propositadamente ou por mera coincidência, Derrida, segundo o qual aquilo de que se não pode falar não se deve calar, mas escrevê-lo, Vergílio Ferreira, tomando a escrita como um processo desencadeador de pensamento, deixou, na recta final da sua carreira literária, dois livros fundamentais, Pensar e Escrever. Quinta-essência e apogeu de todo um laborioso percurso de pensamento e de escrita, assumem-se, a um tempo, estes dois livros como uma espécie de balanço dos procedimentos estético-literários e do pensamento do Autor, na sua qualidade de ficcionista, de ensaísta e de diarista, e ainda como testemunho de um programa de escrita in fieri, como convinha a quem prometera entrar no Paraíso a escrever.

" Professora catedrática de Teoria da Literatura no Departamento de Línguas e Literaturas Modernas da Universidade dos Açores, onde se doutorou com uma dissertação intitulada Romance Lírico. O Percurso de Vergílio Ferreira e um trabalho complementar intitulado Carlos de Oliveira: Artes Poéticas. Tem publicados os seguintes livros: 1) Romance Lírico. O Percurso de Vergílio Ferreira (1990). Grande Prémio de Ensaio da Associação Portuguesa de Escritores; 2) O Trabalho da Prosa (1997); 3) Artes Poéticas (1997); 4) Literatura e Teoria da Literatura em Tempo de Crise (2001). 
Não se tratando embora da imperiosa máxima nulla dies sine linea, é significativo o facto de Vergílio Ferreira ter concebido aqueles livros como diários, tal como nos é paratextualmente indicado em cada um daqueles textos. Mas é também digno de nota (e de reflexão) o facto de os intitular autonomamente, subtraindo-os à respectiva integração na nova série de Conta-Corrente. Tal decisão, tomada pelo escritor em vida ${ }^{1}$, leva-nos a concluir que Pensar e Escrever foram propositadamente destacados do resto da sua produção diarística. E, sabendo nós o que ele foi escrevendo sobre o diário, género circunstancial, feito de sobras e de aparas, aparentemente afastado da cuidadosa elaboração e da nobreza do romance, somos inclinados a situá-los num outro patamar de valorização pessoal. Pensar e Escrever representam, com efeito, o que de melhor Vergílio mostrou saber e gostar de fazer na vida. Ele, que dizia ter «o vício de pensar», exercitou, de forma intensiva, com este empreendimento diarístico de final de carreira, o pendor reflexivo que tão caro lhe era, de forma intransitiva, deixando o pensamento em total liberdade para si dizer e a si próprio se mostrar.

Quando escreveu aqueles dois livros, o Autor já muito tinha praticado tanto a escrita ensaística como a criativa e ficcional. E dessa experiência ter-lhe-á ficado, por um lado, a cada vez mais apurada capacidade de construir obras unitárias de grande fôlego, como $\mathrm{Na}$ Tua Face, o último romance publicado em vida, e de, por outro, desmontar minuciosamente o raciocínio para sondar, de modo fragmentário, mas prismática e profundamente, particularidades da arte e da vida. Trata-se de uma fragmentariedade ${ }^{2}$ de escrita e de pensamento que se acolhe à sombra de um título unificador e remissivo: remissivo, porque nele ecoam os seus anteriores escritos; unificador, porque a forma verbal no infinitivo que o titula, insinuando a descontextualização e a continuidade, sugere igualmente a prossecução e o aprofundamento das habituais obsessões do escritor e bem assim as suas anteriores realizações artísticas e culturais. Na presente situação, assume abertamente o projecto de pensar escrevendo e de escrever pensando, o que, de resto, ele sempre fizera, se bem que noutros moldes.

Nesse infinitivo que titula os dois livros em apreço circula ainda uma outra tendência que a obra romanesca vergiliana já deixara ver: a permanente abstractização que retira ao objecto a respectiva corporização para deixar apenas o cerne de uma significação que é acção, sensação ou pensamento em liberdade, sem sujeito e sem objecto delimitadores. Da flor azul, por exemplo, fica só o azul da flor; da luz que ilumina abstrai-se apenas o gesto de iluminar; dos objectos de pensamento, importa o acto de pensar; para além daquilo que se escreve, importa o gesto de escrever, com todas as implicações que lhe estão ligadas e que em Vergílio são múltiplas.

Também sem contextualização espácio-temporal, embora apontando para o presente da enunciação, é o emprego do infinitivo como expressão de um desejo que é, apesar de tudo, permanente anseio de projecção no tempo e no espaço da 
existência sem mais condicionantes. Estar apenas, condição já escolhida por Paulo, em Para Sempre, como forma de aceitação de uma vida que se cumpre, implica uma concentração ou uma convergência para o sujeito da escrita de tudo o que lhe é exterior. A frase curta, peremptória, fortemente assertiva, diz da melhor forma esta espécie de inércia do sujeito em face do mundo, inversa da intensíssima actividade de pensar e de escrever: «Estar sentado. É a melhor forma de se existir. Ó vós que tendes o mundo a conquistar e grandes ideias a descobrir e grandes obras a realizar, ide, ide. Eu fico. Mas todo o mundo vem assim ter comigo, sem esforço para isso. Que prazer me dá o que for de dar, se tenho de descontar-lhe o meu cansaço? Estou já cansado para poupar o cansaço subsequente. $\mathrm{E}$ as ideias que me importam não são as que exigem um respirar fundo. São ideias frágeis que murcham logo, se lhes tocamos com mãos grossas. São subtilezas que se desvanecem quando as atacamos com energia. São delicadezas para a minha medida, que tem pouca musculatura. Estar sentado. É o meu destino. Cá estou» (FERREIRA, 1992:161).

Em Pensar, Vergílio Ferreira lança as bases deste projecto que Escrever continua e apura, assumindo explicitamente, e de forma condensada, aquilo que a obra vergiliana incessantemente fora dizendo e repetindo: que a escrita era um projecto de arte e uma premente forma de vida. E, num como noutro, se esboça e se cumpre a ideia de que a escrita força à intelecção e à indagação do impensável e do inominável: escrever é dizer o que se sabe e se pensa, mas é também uma tentativa de indagação do que se não sabe e se não pensou. Será também, por essa razão, prenúncio de futuro e abertura para o desconhecido, nessa marcha configurada ou segundo uma vontade de dizer o possível e o visível ou em obediência a um impulso de silenciosa luta com o informulável e o invisível ${ }^{3}$. Por isso, Pensar se apresenta falando, em primeiro lugar, «do impensável» - é este o texto de abertura - e da relação entre linguagem e pensamento e, por extensão, entre linguagem e mundo, porque «problemática alguma se pode estabelecer seja sobre o que for, que não tenha de desenvolver-se dentro dessa língua» (FERREIRA, 1992: 10).

Sendo vários, e todos significativos, os registos discursivos utilizados, serão aqui seleccionados alguns recorrentes e que dizem muito deste processo de escrita/pensamento vergiliano. Na sequência do título, encontramos uma série de fragmentos dominados pela forma infinitiva, que interpretamos genericamente no sentido supra referido, mas que numa leitura mais atenta poderá ser alvo de uma abordagem diferenciada. Sobressai, por outro lado, o fragmento de carácter aforístico ou a máxima, forma que merece a simpatia do escritor ${ }^{4}$.

Vergiliana, por outro lado, é também a tendência, aqui bem evidenciada, para construir um discurso assente numa série de perguntas, que teremos dificuldade em classificar de meramente retóricas, as quais são lançadas sem qualquer expectativa de resposta ou que a trazem implícita sem delongas explicativas ou justificativas ${ }^{5}$. Não deixa este expediente de ser igualmente sintomático do espíri- 
to indagativo - ensaístico, mas também ficcional - vergiliano naquilo que parece uma contradição ou uma aporia ${ }^{6}$. Porque a máxima, como afirmação peremptória, definitiva, contradiz a atitude própria do ensaio (e tanto Pensar como Escrever têm muito deste género discursivo, já noutro local assinalámos, situado a meio caminho entre a reflexão ou a crítica e a literatura) que é de interrogação e procura, em deriva hermenêutica que sabe não ter de (ou não poder) chegar a uma verdade definitiva. Todavia, um intenso convívio com a obra de Vergílio dir-nos-á que a sedução da máxima, pela inadmissibilidade de réplica que lhe é característica, terá de ser lida no pressuposto de que ele entende a intensa vivência de cada momento como se de um absoluto se tratasse. Um absoluto no provisório, contudo, isto é, apto a deslocar continuamente o seu horizonte de verdade de acordo com o tempo que passa. Só assim se aceitará essa posição dominante, não dialogante e com ar de verdade absoluta, a contradizer a interminável «interrogação ao destino» que constitui a magna arquitectura do edifício literário-filosófico do escritor.

No tocante aos modos de enunciação, distinguem-se ainda as entradas em que é empregue o pronome pessoal - umas vezes na primeira pessoa do singular, situação esta que melhor se aproxima da escrita diarística mais ortodoxa, outras do plural - daquelas em que é apenas usado o infinitivo (impessoal, umas vezes, pessoal outras, o que também introduz gradações significativas) e ainda daquelas outras em que é utilizado o discurso abstracto, de carácter aforístico.

As afirmações em primeira pessoa do plural, muito frequentes, dizem bem do anseio de partilhar com o eventual leitor ideias e emoções, numa reflexão que toma como base uma experiência comum, a qual, supõe-se, pretende igualmente uma consonância emotiva ${ }^{7}$ - como, aliás, o pretendia Vergílio com a opção pela primeira pessoa do singular nos romances de narração autodiegética.

Quando está em jogo a condição humana, mesmo que vista na sua óptica, convém-lhe um nós onde todos possam ser acolhidos, muito embora saibamos que é sobretudo ele que está implicado. A razão é que, falando de todos nós, o escritor reenvia simultaneamente, em múltiplas reverberações, à sua própria obra. Não é propriamente um discurso de autocitação que está em jogo, apesar de também esporadicamente ele poder ter lugar ${ }^{8}$ mas o reenvio, sem o dizer, à temática dos seus livros anteriores: à Grande Ordem, por exemplo, a que abaixo se fará referência, ou ao mandato que todos cumprimos, que já vinha bem representado ficcionalmente em Signo Sinal e que em Pensar é reforçado na voz do próprio escritor, a sancionar o que o seu narrador/personagem afirmara: «Todos cumprimos um mandato que nos foi estabelecido na eternidade e não sabemos justificar ou não sabemos qual seja. Nós admiramos uma abelha ou formiga no seu trabalho incognoscível. Mas é no incognoscível que todos nos movemos» (FerReIRA, 1992: 163).

Vergílio Ferreira distingue, porém, os sentimentos, as sensações e os conhecimentos que são do domínio colectivo das suas verdades intensamente vividas 
ou «verdades de sangue», como gostava de as classificar. Assim se justifica a introdução, talvez mais em Escrever do que em Pensar, de entradas de tipo diarístico ou tão-só a referência a aspectos da sua posição como escritor: o mal-estar, por exemplo, que o toma quando vê um livro seu numa estante alheia. Porém, esse desabafo pessoal, frequente, serve como porta de entrada para considerações mais alargadas sobre a condição de todo o artista: debatendo-se, por um lado, com o dilema de se sentir estranho nas mãos de outrem, querendo preservar a sua intimidade, e de, por outro lado, desejar ser lido e conhecido. Atitude para a qual arranja de imediato uma desculpa, que serve de fecho ao fragmento.

Este processo de estruturação interna dota os fragmentos de uma unidade constituída por um problema, uma questão, mas também um dado retirado da experiência de vida do escritor, tomado como nota de abertura e que vai sendo desenvolvido até finalizar com uma síntese conclusiva e generalizante. O dado inicial do fragmento 53 (o mal-estar que o toma quando vê um livro na estante de alguém) importa menos como experiência pessoal do que motivação para o que a seguir se justifica. Porque o particular é alçado, processo recorrente em Vergílio, a um domínio em que se dilui no universal da condição humana ou da condição da arte: «E todavia é isso mesmo que como autores todos nós desejamos - a sua divulgação, a participação dos outros no milagre que nos visitou, $o$ reconhecimento de que foi em nós que ele aconteceu. É o mistério da obra de arte, a sua reserva e a sua publicidade, o ser de fora sem o ser. É o mistério ou o paradoxo do artista, que não deseja violado o mais íntimo de si e exige ou necessita de que seja conhecido. É a sorte de uma religião que reduz à positividade do dizível o sagrado e invisível de antes dela...» (FERREIRA, 1992: 55).

Nem sempre, porém, ele pretende seguir acompanhado, havendo, da sua parte, a frequente assunção de um pensamento em liberdade, por conta própria, numa formulação discursiva à qual imprime a forte marca autoral. É isso visível sobretudo na expressão dos seus temas recorrentes, como o da "Grande Ordem», sua antiga obsessão, dita tanto no romance como no ensaio, mas agora submetida à lógica do pensar que dá o título ao livro: «A Grande Ordem. É um impensável. Porque é um limite do pensar tudo o que é tem a sua morada lá onde duas paralelas se encontram. É onde se saldam todas as contas do que somos e fazemos. É o irredutível do ser, o inultrapassável de quanto se possa ultrapassar. O sentido final de todo o não-sentido. A nula face de todos os deuses que já a não têm senão para a nossa necessidade de sermos reais. Um nome sem nome» (FerREIRA, 1992: 160).

Quando exprime emoções pessoais ou juízos de valor, o escritor dispensa igualmente companhia, parecendo não ter necessidade dela. Talvez porque a emoção e o encantamento são para serem fruídos individualmente, e, acima de tudo, porque aquilo que se evidencia é da ordem da profundeza do ser e não pressupõe a colectividade. É certo que, em algumas ocasiões, o «eu» surge um 
pouco diluído num «nós», mas vem integrado numa expressão onde se percebe claramente a voz individual, perfeitamente reconhecível, do diarista ou ensaísta Vergílio Ferreira, sendo esta perspectiva individual que sobreleva. A nossa presença é, pois, tolerada, por arrastamento, só na medida em que com ele concordarmos. Nesta apreciação da música barroca, por exemplo (fragmento 215): "Que bela a música barroca. Tem um registo breve para a alegria ou tristeza. Mas cabe lá todo o possível. Normalmente é de uma terna melancolia, sem grande tragédia ou exaltação. Sem excessos, sem grandiloquência. E tudo quanto em nós pode a ela reagir é apenas um breve sorriso para dentro e que se não sabe se é triste, se de simples pacificação» (FERREIRA, 1992: 161).

Porém, quando se trata da arte em geral, talvez por admitir que todos estão em consonância com ele, é a generalização que se manifesta, se bem que de dois modos dissemelhantes: ou parte da sua experiência pessoal para a abstracção, formulando asserções de alcance universal, ou, ao contrário, parte de um conceito ou de uma constatação abrangente para seguidamente os cingir ao seu caso, mesmo se nem sempre o discurso pessoal fica expresso. O fragmento 219 de Pensar é um bom exemplo disso mesmo, porquanto somos forçados a não ignorar, ou a imaginar, o escritor Vergílio Ferreira com «a emoção ao lado para nela ir enchendo a caneta»: "O difícil em arte é criar-se emoção sem se mostrar que se está emocionado. Ou estar emocionado para antes e depois de se estar. Ou ter a emoção ao lado para nela ir enchendo a caneta» (FerREIRA, 1992: 163).

A dádiva deste pensar, que nos assim é concedida, na diversidade dos seus fragmentos, exige, contudo, também uma resposta da nossa parte, enquanto leitores receptivos à mensagem que nos é endereçada. Daí que estes «diários» não o sejam exactamente, pela abrangência temática e enunciativa que os sustenta e sobretudo porque os fragmentos que os constituem não são exclusivamente de tipo diarístico.

Ao contrário do que no diário, na sua formulação mais comum e mais esperada, acontece, o dia nunca é explicitado e muito raramente, e só de forma vaga, temos acesso a informação sobre a situação do escritor ou sobre as condições da escrita, tão-pouco nos fragmentos em que esta é convocada como tema de reflexão. E convidam-nos, tanto Pensar como Escrever, a uma activação de saberes arquivados na nossa memória cultural - sobre a obra do escritor, sobre a arte, a cultura, a filosofia, os problemas do nosso tempo. Convidam-nos, em suma, a pensar, exigindo um comprometimento diferente daquele que estabeleceríamos com os volumes de Conta-Corrente, não obstante a reflexão de ordem supra-individual que, por entre o relato das vivências do quotidiano - desta vez, precisas e bem localizadas temporal e espacialmente -, também os atravessa.

Em várias entradas Vergílio opera um balanço desencantado das ideias que a sua vasta obra foi disseminando. Como se, depois de tudo dito, sentisse que tudo ficara ainda por dizer. Anote-se, aliás, que a redundância lhe foi sendo um 
recurso estilístico cada vez mais caro, porque, escreveu um dos seus narradores/ /personagens, «o que se repete cria o sem-fim e a eternidade».

O grande mérito destes livros, tão profundos e tão apelativos, estará, certamente, na retoma de tudo o que o Autor escrevera anteriormente e ainda assim aqui apresentado com notável frescura e novidade porque em novo contexto, em fragmentos que, independentes, querem ser nova maneira de reacentuar o idêntico. A reinsistência no mesmo sugere então que se não mudou de problemática; apenas se foi modulando a respectiva formulação.

Lidos (ou relidos) sem necessidade de ordem, sem obediência a cronologia, seja narrativa seja diarística, sem hierarquização, esses fragmentos oferecem em permanência uma leitura em duplo sentido: ou tomando cada um deles como uma micro-unidade que se fecha numa significação que vale por si, independentemente do que a precede ou do que se lhe segue; ou tomando-os como parte de um todo que, no seu conjunto, adquire um sentido unitário.

Resta dizer que esta ânsia de unidade sempre foi timbre do pensamento vergiliano e desiderato presente na sua obra ficcional, apesar da fragmentariedade, mais visível e mais apurada nos seus romances da última fase, que a estrutura à superfície. Por mais de uma vez escreveu, na esteira de Camus, que a nossa época «é louca de unidade» e repete-o, assim, em Pensar, um dos livros que precisamente apostou na forma menos unitária. E é «louca de unidade» porque vivendo um tempo em que esta mais esconde a sua face. Daí o teor do fragmento 415: «Nós somos os fragmentos de não sabemos que unidade. Nós somos órgãos dispersos de não sabemos que organismo. Soubemos unificar as constelações, a dispersão dos seres, talvez a do universo. Mas somos incapazes de unificar o nosso tempo. Nós não temos unidade e dela estamos "loucos", disse Camus» (FERREIRA, 1992: 259).

Nesta lógica, Pensar, e também Escrever, constituem, em última instância, mais uma peça fundamental para a interpretação do pensamento de Vergílio Ferreira e para o conhecimento da sua obra como um trabalho que, constituindo-se em progressão e em acto de escrita e de pensamento, se afirma, no final, como obra acabada, no duplo sentido do termo: feita e perfeita. E, acrescente-se, com a morte do escritor, definitiva. Definitiva enquanto labor escritural, que não enquanto dádiva de sentidos, porquanto estes continuam a ser oferecidos ao leitor.

Em conclusão, depois de tudo o que pensou e escreveu, de todos os mundos alternativos que na ficção criou para neles habitar (e para neles habitarmos também), restava-lhe, uma vez mais, pensar. Apenas isso e escrever, que é o seu modo de não deixar de pensar. Daí a continuação desse primeiro diário, «do acaso de ir pensando» em Escrever, diário do acaso de ir escrevendo, actividades inseparáveis e complementares. 
${ }^{1}$ A propósito de Pensar, porquanto Escrever é de edição póstuma (2001).

${ }^{2}$ Sobre a escrita do fragmento em Vergílio Ferreira, cf. Fonseca, 2004: 345-362 e Goulart, 2007: 115-130.

${ }^{3}$ Eduardo Lourenço, com a sua fulgurante intuição, sempre apoiada em vastíssima cultura, assinala o lado subterrâneo destes pensamentos, de tal modo que nem sempre se destrinçam neles luminosidade e obscuridade, ideia e não-ideia ou, na linguagem brandoniana, húmus: «Todavia, o mais interessante na sua obra e tantas vezes reiterado nas suas reflexões, sobretudo nas mais espontâneas ou desenvoltas, como as de Pensar, é o facto de que esse pathos especulativo se acompanha de um contraponto, de um reflexo, o reflexo de base, de desconfiança em relação às ideias ou à ideia, precisamente. Nessa esfera dos puros pensamentos ou da alta especulação, onde o sentido das coisas, ou a cifra do nosso pessoal destino, devia adquirir o perfil mais luminoso, é que tudo se obscurece. Sob a ideia, mais primordial e mais irredutível que ela, a não-ideia, ou, para evocar um termo dos raros autores que ela realmente admitia e a quem se assimila, Raul Brandão, o húmus (LOURENÇO, 1996: 355)

" Sobre a máxima escreveu assim Vergílio Ferreira no fragmento 263: «Não há como a "máxima" para se impor e fixar. Ou simplesmente a frase categórica, a que afirma e não "discute". Pode ser falsa, inconsequente ou mesmo tola. Porque se aguenta mesmo assim. A gente defronta-se com ela e é "pegar ou largar". Tem a forma escarpada de uma rocha a que se não pode subir. Ou a redondeza de uma esfera em que se não pode firmar a mão» (FErreIRA, 1992: 187). E Helena Topa (TopA, 2003: 25-26), por sua vez, citando Gerhard Neumann, expõe nos seguintes termos (aplicáveis, em certa medida, a Vergílio Ferreira) o entendimento daquele autor quanto ao aforismo, que assenta basicamente num confronto entre «a experiência particular do aforista e a sua consciência do que é o geral, podendo geral aqui ser lido como o senso comum, a regra, o paradigma». Daí se deduz a atitude do escritor perante o conhecimento, o qual pressupõe a regra ou a lei, mas se afirma ao mesmo tempo contra ela: «Em cada aforismo, o autor joga radicalmente a sua independência de pensamento, a lei do seu saber individual, em cada texto testa os limites e o alcance da sua experiência contra o saber instituído e, em última instância, das suas possibilidades de conhecer tout court. O aforismo ergue-se, assim, em paradigma de um conhecimento novo, ou antes, num novo paradigma de conhecimento, um saber livre porque contorna voluntariamente os constrangimentos da construção sistemática do discurso.»

${ }^{5}$ Cf. Ferreira, 1992: 259 (fragmento 414): «A tragédia só existe em face do que a nega. Em face de quê o jovem de hoje há-de entender a tragédia de hoje?»

${ }^{6}$ Não são, aliás, raras estas «contradições», tanto no livro em análise como no resto da obra. Como nos lembra ainda Eduardo Lourenço, que sublinha aquela que desemboca aporeticamente no dissídio entre finitude e infinitude: «Toda a obra de Vergílio Ferreira ficcionará sem fim - mas aprofundando e deslocando no sentido da própria extenuação dela - a aporia aparentemente sem solução entre a finitude, inscrita na mortalidade e mitificada na Morte como horizonte incontornável da vida - da nossa, que é o que importa - e a consciência da infinitude, ou melhor, a eternidade que parece consubstancial à mesma vida, consciente de si, simultaneamente existência e pensamento" (LOURENÇO, 1995: $358)$.

${ }^{7}$ Cf. Ferreira, 1992: 54: «Dor, amargura, melancolia. Quantas formas de se ser vencido no que desejávamos. Mas ao longo delas, o que varia é a parte de nós que se submete. E mesmo a parte perversa de nós que se contenta com isso. Assim o que varia é a parte de nós que se mede com o destino. Mas com isso não variará também a qualidade do sofrimento?»

${ }^{8}$ Cf. Ferreira, 1992: 151: «Sim, a arte esclarece-nos sobre o significado de uma época, é o ponto terminal da sua expressão. Mas neste jogo do ovo e da galinha, como saber quem 
começou? A arte apura a água que a vida lhe forneceu e depois há-de beber - escrevi um dia.» Temos ainda no fragmento 300 de Pensar, que se reporta a uma contemplação no presente da escrita, uma descrição poética que nos faz evocar muitas páginas do romance vergiliano, nomeadamente Rápida, a Sombra (1974), onde encontramos outro raio de sol (ou o mesmo, infinitamente repetido, como é próprio de Vergílio, e como ele não deixa aqui de insinuar?) a passear-se vagarosamente pelas estantes: «Desce por entre os pinheiros o sol da tarde, derrama-se pelo escritório, embate numa estante de livros. Na prateleira do fundo há uma série deles de lombada branca. É onde o sol mais gosta de se instalar. O branco dos livros aviva-se extraordinariamente, tem o desdobramento de uma cal intensa, de um leite fresco iluminado por dentro. Mil vezes eu já vi esta iluminação de vertigem e já a terei anotado. Mas ela tem em si um milagre bastante para ser sempre pela primeira vez» (p. 209).

Ferreira, Vergílio. Pensar, Lisboa, Bertrand, 1992.

- Escrever, Lisboa, Bertrand, 2001.

Fonseca, Fernanda Irene. «Fragmentação e unidade: contributo para a análise de formas textuais intencionalmente fragmentárias». In: Oliveira, Fátima e Duarte, Isabel Margarida (org.). Porto: Campo das Letras, 2004, pp. 345-362.

Goulart, Rosa. "A escrita do fragmento: ensaio, diário ou "romance aos quadradinhos"? In: Cordeiro, Cristina Robalo e Simões, Maria João (coord.). O Texto Breve: Para Uma Abordagem Diferencial. Coimbra: Centro de Literatura Portuguesa, 2007, pp. 115-130.

Lourenço, Eduardo. «Pensar Vergílio Ferreira». In Vergílio Ferreira. Cinquenta Anos de Vida Literária. Porto: Fundação Eng. ${ }^{\circ}$ António de Almeida, 1995, pp. 353-360.

Topa, Helena. A Palavra de Fogo. Uma Leitura Contextualizante da Prosa Breve de Elias Canetti. Lisboa: Fundação Calouste Gulbenkian/Fundação para a Ciência e a Tecnologia, 2003. 
